\title{
P-glycoprotein Expression Is Upregulated in a Pre-Clinical Model of Traumatic Brain Injury
}

Sydney M. Vita, ${ }^{1, *}$ John B. Redell, ${ }^{2}$ Mark E. Maynard, ${ }^{2}$ Jing Zhao, ${ }^{2}$ Raymond J. Grill, ${ }^{1}$

Pramod K. Dash, ${ }^{2}$ and Bernadette E. Grayson ${ }^{1}$

\begin{abstract}
Athletes participating in contact sports are at risk for sustaining repeat mild traumatic brain injury (rmTBI). Unfortunately, no pharmacological treatment to lessen the pathophysiology of brain injury has received U.S. Food and Drug Administration (FDA) approval. One hurdle to overcome for potential candidate agents to reach effective therapeutic concentrations in the brain is the blood-brain barrier (BBB). Adenosine triphosphate (ATP)-binding cassette ( $A B C$ ) transporters, such as P-glycoprotein (Pgp), line the luminal membrane of the brain capillary endothelium facing the vascular space. Although these transporters serve to protect the central nervous system (CNS) from damage by effluxing neurotoxicants before they can reach the brain, they may also limit the accumulation of therapeutic drugs in the brain parenchyma. Thus, increased Pgp expression following brain injury may result in reduced brain availability of therapeutic agents.

We therefore questioned if repeat concussive injury increases Pgp expression in the brain. To answer this question, we used a rodent model of repeat mild closed head injury ( $\mathrm{rmCHI})$ and examined the messenger RNA (mRN) and protein expression of both isoforms of rodent Pgp (Abcb1a and Abcb1b). Compared with sham-operated controls $(n=5)$, the mRNA levels of both Abcb1a and Abcb1b were found to be increased in the hippocampus at day $1(n=5)$ and at day $5(n=5)$ post-injury. Using a validated antibody, we show increased immunolabeling for Pgp in the dorsal cortex at day 5 and in the hippocampus at day $1(n=5)$ and at day $5(n=5)$ post-injury compared with sham controls $(n=6)$. Taken together, these results suggest that increased expression of Pgp after rmCHI may reduce the brain accumulation of therapeutic drugs that are Pgp substrates. It is plausible that including a Pgp inhibitor with a candidate therapeutic agent may be an effective approach to treat the pathophysiology of rmCHI.
\end{abstract}

Keywords: blood-brain barrier; hippocampus; P-glycoprotein; traumatic brain injury

\section{Introduction}

Traumatic brain injury (TBI) is a major health care problem in the United States, with more than 2 million new cases occurring annually. ${ }^{1}$ Brain injury can be classified by severity level (i.e., mild, moderate, or severe) and/or mechanism (e.g., direct impact, penetrating, or acceleration/deceleration). ${ }^{2,3}$ It has been estimated that more than $75 \%$ of TBI cases are classified as mild (mTBI), also commonly referred to as concussion. ${ }^{4,5}$
Although most patients report the abatement of symptoms within 3 months, as many as 33\% may experience persistent symptoms for months or years post-injury. ${ }^{6}$ The mechanisms through which mTBI alters brain function and pathology at various time-points are not well understood and are an intense area of study.

Currently, there are no effective therapeutics available to lessen TBI pathobiology and improve brain function. One hurdle for candidate agents to overcome

\footnotetext{
${ }^{1}$ Department of Neurobiology and Anatomical Sciences, University of Mississippi Medical Center, Jackson, Mississippi, USA.

${ }^{2}$ Department of Neurobiology and Anatomy, University of Texas McGovern Medical School, Houston, Texas, USA.
}

*Address correspondence to: Sydney Vita, BA, Department of Neurobiology and Anatomical Sciences, University of Mississippi Medical Center, 2500 North State Street, Jackson, Mississippi, USA, Email: svita@umc.edu

(C) Sydney M. Vita et al., 2020; Published by Mary Ann Liebert, Inc. This Open Access article is distributed under the terms of the Creative Commons License (http://creativecommons.org/licenses/by/4.0), which permits unrestricted use, distribution, and reproduction in any medium, provided the original work is properly credited. 
is crossing the blood-brain barrier (BBB) to reach the brain. Research into spinal cord injury (SCI) offers a mechanism by which central nervous system (CNS) availability of pharmacological agents can be restricted. SCI creates a condition reminiscent of chemotherapeutic resistance, ${ }^{7}$ a pathological condition first described in tumors that develop resistance to drugs due to upregulation of P-glycoprotein (Pgp). Pgp is a broad specificity adenosine triphosphate (ATP)-dependent efflux pump that can bind to hundreds of different substrates (including therapeutic drugs) and pump them out of the tissue. ${ }^{8}$ As a result, systemically administered drugs may not be able to achieve a concentration in the injured spinal cord sufficient to exert therapeutic effects. This phenomenon has also been shown to occur under other pathological conditions, such as in a mouse model of amyotrophic lateral sclerosis (ALS). It has been demonstrated that Pgp is responsible for limiting the bioavailability of riluzole, a U.S. Food and Drug Administration (FDA)-approved treatment for ALS, and that co-administering riluzole with a Pgp inhibitor improves treatment efficacy. ${ }^{9,10}$

In humans, a single, severe TBI has been reported to acutely increase the expression of Pgp in pericontusional brain biopsy samples. ${ }^{11}$ Similarly, a significant increase in Pgp expression has been seen at the site of injury 3 days following experimental SCI. ${ }^{7}$ However, it has not been investigated if mTBI, particularly repeat mild TBI (rmTBI), alters Pgp expression. In the current study, we test the hypothesis that rmTBI will elicit an upregulation of Pgp, suggestive of a chemotherapeutic resistant-like state. We chose to evaluate Pgp expression at 1 day and 5 days post-injury as some patients with concussion may seek care acutely after injury, whereas others may delay and only seek care if symptoms worsen, or do not resolve.

\section{Methods}

Animal assurance

All animal care and experimental procedures were conducted in accordance with the "Guide for the Care and Use of Laboratory Animals" of the National Institutes of Health and approved by the Institutional Animal Care and Use Committee of the University of Texas Health Sciences Center.

\section{Animals}

We utilized male Mdr1a/ $\mathrm{b}^{-/-}$constitutive knockout (KO) mice bred on an FVB background (FVB.129P2Abcbla ${ }^{\text {tm1Bor }}{ }^{-}$bcbl $1 b^{\text {tm1Bor }}$, Taconic Biosciences, Ger- mantown, NY, USA) and wild type (WT) controls for our antibody validation studies. C57BL/6 male mice (12-16 weeks old; Jackson Laboratories, Bar Harbor, ME, USA) were used for all other experiments. All animals were housed singly on a 12-h light/dark cycle with ad libitum access to food and water.

Injury

Repeat, mild closed head injury ( $\mathrm{rmCHI}$ ) was delivered using a pneumatically driven controlled cortical impact (CCI) device, as previously described. ${ }^{12,13} \mathrm{C} 57 \mathrm{Bl} / 6$ mice (20-25 g, $n=31)$ were anesthetized initially with $5 \%$ isoflurane in a $1: 1 \mathrm{O}_{2}$ /air mixture, and then maintained on a $2.5 \%$ isoflurane and 1:1 $\mathrm{O}_{2}$ /air mixture via a face mask. Animals were mounted on a stereotaxic frame to provide stability as a midline incision was made on the scalp, and the soft tissue was reflected to expose the skull. The mouse was then transferred to a foam pad designed to hold the head at a level plane with the body. Anesthesia was discontinued for $20 \mathrm{sec}$ (the time required to regain a tail pinch reflex) before a $5-\mathrm{mm}$ diameter metal tip delivered a single impact to the skull. The impact was made over the sagittal suture, midway between lambda and bregma, at a velocity of $5.0 \mathrm{~m} / \mathrm{sec}$ to a depth of $1.0 \mathrm{~mm}$. After normal breathing was observed, the scalp was closed using sterile surgical staples. Mice received one injury per day for 4 consecutive days. Sham mice received daily isoflurane anesthesia but were not injured. Total number of mice used for experiments is as follows: $n=11$, sham; $n=10$, euthanized 1 day following 4 consecutive days of injury ( 1 day rmCHI); and $n=10$, euthanized 5 days following 4 consecutive days of injury ( 5 days rmCHI).

\section{Euthanasia and tissue processing}

Western blot analysis. Total protein homogenates were prepared from constitutive $\mathrm{Mdrla} / \mathrm{b}^{-/-}$mice and controls as previously described. ${ }^{13}$ Total protein concentration was measured by bicinchoninic acid (BCA) assay using bovine serum albumin (BSA) as the reference standard. Sample aliquots were diluted into $1 \times$ Wes sample buffer and protein content equalized. Target proteins were quantified using an automated capillary immunoassay system (Wes, Protein Simple, San Jose, CA, USA).

Brain harvest for RNA. At 1 day $(n=5)$ and 5 days $(n=5)$ following the final injury, or 1 day $(n=3)$ and 5 days $(n=2)$ following sham procedure, animals were rapidly decapitated, brains were removed, hippocampi 
were quickly dissected out on ice, and tissues were frozen on dry ice in Eppendorf tubes. Tissues were stored at $-80^{\circ} \mathrm{C}$ until needed for processing.

\section{RNA isolation and real-time polymerase} chain reaction

RNA was extracted using a QIAGEN miniprep RNA kit (QIAGEN, Inc., Valencia, CA, USA), and concentration of total RNA was determined by NanoDrop Lite (Thermo Scientific). Complementary DNA (cDNA) was generated from $1000 \mathrm{ng}$ total RNA using an iScript cDNA synthesis kit (Bio-Rad Laboratories, Hercules, CA, USA). Quantitative polymerase chain reaction (PCR) was performed on a Step-One Plus Real-Time PCR (RT-PCR) instrument running StepOne software (version 2.3, Applied Biosystems) using TaqMan inventoried gene expression assays (Life Technologies, Foster City, CA, USA) as listed in Table 1. Samples were analyzed in duplicate and the change in threshold cycle $\left(\mathrm{C}_{\mathrm{T}}\right)$ values from the reference control (L32) was calculated. Values obtained for the control group were averaged and made to equal 100 for presentation purposes.

\section{Immunohistochemistry}

At 1 day $(n=5)$ and 5 days $(n=5)$ following the final injury, or 1 day $(n=3)$ and 5 days $(n=3)$ following sham procedure, animals were deeply anesthetized using intraperitoneal sodium pentobarbital $(100 \mathrm{mg} / \mathrm{kg})$. Once animals failed to respond to toe and tail pinch, they were transcardially perfused with ice-cold saline followed by decapitation. Brains were removed and flash frozen in $-80^{\circ} \mathrm{C}$ isopentane (2-methylbutane). Cryosections ( $20 \mu \mathrm{m}$ thick) were prepared using a cryostat and were directly mounted onto Leica $A_{p e x}{ }^{\mathrm{TM}}$ Superior Adhesive Slides (Leica Biosystems, Buffalo Grove, IL, USA). Slides were stored at $-20^{\circ} \mathrm{C}$ until needed for processing. Three sections per animal corresponding to approximately bregma $1.80 \mathrm{~mm}$ were postfixed in $100 \% \mathrm{MeOH}$ methanol for $10 \mathrm{~min}$ at $-20^{\circ} \mathrm{C}$, then allowed to dry. All subsequent steps were completed at room temperature. Tissues were permeabilized for $45 \mathrm{~min}$ in phosphate-buffered saline (PBS) $+0.25 \%$ Triton, then blocked in PBS $+5 \%$ normal goat serum for $1 \mathrm{~h}$. Primary antibodies were diluted in $\mathrm{PBS}+2.5 \%$ goat serum to a final concentration of $7 \mu \mathrm{g} / \mathrm{mL}$ and were incubated overnight. After extensive washing in PBS, sections were incubated for $2 \mathrm{~h}$ in corresponding secondary antibodies conjugated to an Alexa Fluor dye for visualization (final concentration of $2 \mu \mathrm{g} / \mathrm{mL}$ ). Finally, sections were washed for $2 \mathrm{~min}$ in bisbenzimide (\#382061, Calbiochem) diluted to $1 \mu \mathrm{g} / \mathrm{mL}$ in $1 \times \mathrm{PBS}$.

\section{Immunolabeling analysis}

Fluorescent sections were imaged using an Axioscan.Z1 slide scanning microscope (Zeiss, Thornwood, NY, USA) equipped with an X-Cite XLYS LED light source (Excelitas Technologies, Waltham, MA, USA) and custom filter sets (Semrock). Images were captured using a $20 \times / 0.8$ NA Plan-Apochromat objective lens (Zeiss) and ORCA-Flash4.0 sCMOS digital camera (Hamamatsu) at $325 \mathrm{~nm} /$ pixel resolution and were montaged using Zen Blue 2.3 software. Exposure and gain were adjusted using a representative section from a shamoperated animal and were kept constant across all groups. Fluorescence intensity signals for each region of interest (ROI) were quantified for each hemisphere and then averaged. Bisbenzimide staining was used as a guide to trace the ROIs in ImageJ. ROIs were identified using a mouse brain atlas. ${ }^{14}$ Off-target fluorescence intensity was measured for each section, averaged, and subtracted from the target signal for quantification. The corrected intensity was then averaged across the three sections for each animal and data (mean \pm standard error of the mean [SEM]) presented relative to Sham (set to $100 \%$ ).

\section{Antibodies}

The following antibodies were used in these studies: anti-Pgp antibodies (\#ab170904, \#ab3366, AbCam, Cambridge, MA; and MA1-26528, Thermo Scientific), astrocytic marker glial fibrillary acidic protein (GFAP; custom, Bethyl, Montgomery, TX, USA), microglia marker Iba1 (\# 234004, Synaptic Systems), tight junction marker occludin (\#33-1500, Thermo Scientific), and neuronal marker NeuN (Millipore, \# ABN91). Species-specific secondary antibodies linked to Alexa Fluor dyes (Alexa Fluor 488, Alexa Fluor 594, and AlexaFluor 647) were purchased from Thermo Fisher Scientific.

\section{Statistical analysis}

All statistical analyses were performed using GraphPad Prism version 8.3.1 (GraphPad Software, San Diego, California, USA). When testing across time, a oneway analysis of variance (ANOVA) was performed followed by post hoc analysis. Differences between two groups were assessed using an unpaired Student's $t$ test with a two-tailed distribution. Results were considered significant at $p<0.05$, and data are shown as mean \pm SEM. 


\section{Results}

rmCHI triggers an inflammatory response

but does not cause overt neuronal loss

To examine for overt neuronal loss after rmCHI, tissue sections from sham (Fig. 1A) and rmCHI (Fig. 1B) mice were stained for NeuN (a marker of neurons). GFAP immunoreactivity was used to examine the inflammatory response after rmCHI. Representative images from a sham and rmCHI mouse are shown in Figure 1. Visual examination of NeuN signal intensity and localization did not reveal any areas with overt evidence of neuronal cell loss, whereas enhanced GFAP immunoreactivity was readily apparent throughout the hippocampus and overlying corpus callosum, in addition to some increased staining in the cortex, as we and others have previously observed. ${ }^{12,13,15,16}$ Increased immunoreactivity of the microglial marker Iba-1 was also observed in the hippocampus, overlying white matter and cortex.

rmCHI increases Pgp mRNA expression in the hippocampus

Pgp is a member of the ABC family of transport proteins, with two isoforms (Abcbla and Abcblb) expressed in
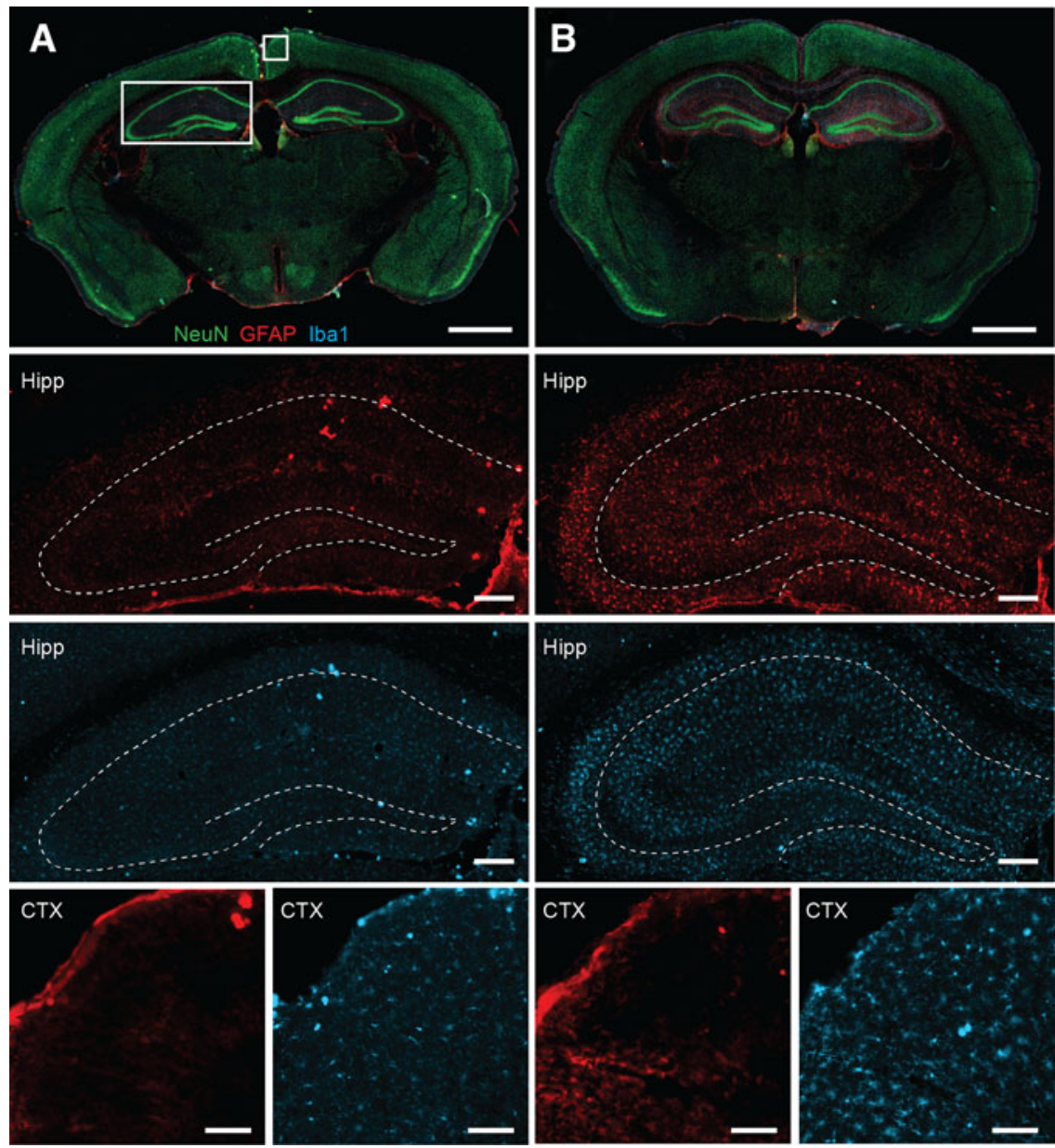

FIG. 1. rmCHI triggers an inflammatory state but not overt neuronal cell loss. Representative images of brain sections from (A) sham and (B) rmCHI animals $24 \mathrm{~h}$ after the last injury or sham surgery, stained with the neuronal marker NeuN (green), the astrocyte maker GFAP (red), and the microglial marker lba-1 (blue). The boxed areas in $(\mathbf{A})$ indicate the regions of the cortex and hippocampus that are shown in the higher magnification panels. Dashed lines indicate the position of the CA1/3 and dentate granule cell body layers in the hippocampus. Scale bars: whole brain panel: $1 \mathrm{~mm}$; hippocampus panels: $200 \mu \mathrm{m}$; cortex panels: $100 \mu \mathrm{m}$. GFAP, glial fibrillary acidic protein; $\mathrm{rmCHI}$, repeat mild closed head injury. 
rodents. To examine if rmCHI alters Pgp messenger RNA (mRNA) expression, brain tissues were collected 1 or 5 days after the last injury, and total RNA was extracted and used for quantitative RT-PCR analysis using isoform-specific primers (Table 1). Ribosomal RNA L32 was used as an internal reference for sample to sample normalization. Results presented in Figure 2 show the time course for mRNA changes in Abcbla and Abcblb mRNA levels in the hippocampus, a structure critical for learning and memory that is vulnerable to TBI. Abcbla mRNA in the hippocampus was significantly increased in rmCHI animals as compared with sham (one-way ANOVA, $\mathrm{F}_{(2,12)}=11.50$ ) by 1 day post-injury $(p<0.01)$, and was further increased to greater than twofold by 5 days post-injury $(p<0.01$; Fig. 2A). Abcblb mRNA showed a similar response after rmCHI (one-way ANOVA, $\mathrm{F}_{(2,12)}=10.39$ ), with a significant increase observed by 1 day post-injury $(p<0.05)$, and a greater response observed by 5 days post-injury $(p<0.01$; Fig. $2 \mathrm{~B})$. To determine if this might be a generalized response to traumatic injury, we next assessed the mRNA expression levels of two related $\mathrm{ABC}$ transporter superfamily members, Abcg2 and Abcc1. Abcg2, also known as breast cancer resistance protein, or BCRP, showed a non-significant upward trend in mRNA expression $\left(\mathrm{F}_{(2,12)}=3.10\right.$; $p=0.085$; Fig. 2C), whereas Abccl exhibited the opposite $\left(\mathrm{F}_{(2,12)}=2.76 ; p=0.107\right.$; Fig. $\left.2 \mathrm{D}\right)$.

\section{Authentication of Pgp antibodies}

We attempted to assay Pgp expression in hippocampal and cortical homogenates using a commercially available enzyme-linked immunosorbent assay (ELISA) kit (\#LS-F12021-1, LSBio, Seattle, WA, USA). Although the standard curve that was generated using reagents supplied with the assay showed a linear increase in sig-

Table 1. Primers for PCR

\begin{tabular}{lcc}
\hline Name & Gene symbol & Assay ID \\
\hline Pgp a & Abcb1a & Mm00440761_m1 \\
Pgp b & Abcb1b & Mm00440736_m1 \\
BCRP & Abcg2 & Mm00496364_m1 \\
Mrp1 & Abcc1 & Mm00456156_m1 \\
Mrp4 & Abcc4 & Mm01226381_m1 \\
Mrp5 & Abcc5 & Mm01343626_m1 \\
Mrp6 & Abcc6 & Mm00497698_m1 \\
Claudin 1 & Cldn1 & Mm01342184_m1 \\
Claudin 5 & Cldn5 & Mm00727012_s1 \\
Occludin & Ocln & Mm00500912_m1 \\
Zo-1 & Tjp1 & Mm01320638_m1 \\
L32 & Rpl32 & Mm02528467_g1 \\
\hline
\end{tabular}

$\mathrm{BCRP}$, breast cancer resistance protein; $\mathrm{PCR}$, polymerase chain reaction; Pgp, P-glycoprotein. nal with increasing protein concentration, we found the results obtained using brain tissue extracts were highly variable. We therefore questioned if antibody specificity might contribute to the variability we observed. To address this, Mdr1a/1 $\mathrm{b}^{-/-}$constitutive dual KO mice (with Mdr1a exons 3-4 disrupted with a hygromycin targeting cassette, and $M d r 1 b$ exons 3-4 disrupted by a neomycin targeting cassette ${ }^{17}$ ) were purchased, and brain extracts prepared for ELISA and western blot analysis. Brains from WT FVB mice were used as a control. Equal amounts of $\mathrm{KO}$ and WT brain homogenate were tested by ELISA, and a strong immunoreaction was detected in $\mathrm{Mdr} 1 \mathrm{a} / \mathrm{b}^{-/-}$mice (Supplementary Fig. S1A). Similarly, when extracts from WT and $\mathrm{KO}$ mice were run in a capillary western blot, immunoreactive bands were detected in both brain tissues, suggesting that the anti-Mdrl antibody supplied with the kit may be non-specific (Supplementary Fig. S1B).

We therefore screened three different commercially available Pgp antibodies and verified one (Abcam \#ab170904) as being selective for Pgp in western blot and immunohistochemistry. Figure $3 \mathrm{~A}$ shows a representative capillary western blot using this antibody indicating the linearity of Pgp immunoreactivity in relationship to different amounts of starting material (WT cortical extract). The $180 \mathrm{kDa}$ band was not observed in brain extracts from $\mathrm{Mdrla} / \mathrm{b}^{-/-}$mice (Fig. 3B). We then stained WT and Mdrla $/ 1 b^{-/-}$brain sections for occludin (tight junction protein expressed on microvessels) and Pgp (\#ab170904). Figure 3C shows that Pgp and occludin co-labeled microvessels in the WT brain, but Pgp immunoreactivity was absent in microvessels in the KO brain sections. Although several studies have used the mouse monoclonal antibody (C219; \#MA1-26528), ${ }^{18-22}$ the rabbit monoclonal antibody (\#ab170904) provided the most robust western blot and immunohistochemistry signals in our hands.

$\mathrm{rmCH}$ is associated with increased Pgp

immunoreactivity in the dorsal cortex

and the hippocampus

Using the validated antibody, we examined the spatial changes in Pgp immunoreactivity following rmCHI. Figure 4A shows representative montaged images of Pgp immunoreactivity in the dorsal cortex of sham, 1-day post-rmCHI, and 5-day post-rmCHI mice. Pgp immunoreactivity was significantly increased by 5 days post-rmCHI in cortex proximal to the injury location $\left(\mathrm{F}_{(2,13)}=14.37 ; p<0.01\right)$. In the hippocampus (Fig. 4B), Pgp immunoreactivity on microvessels was 

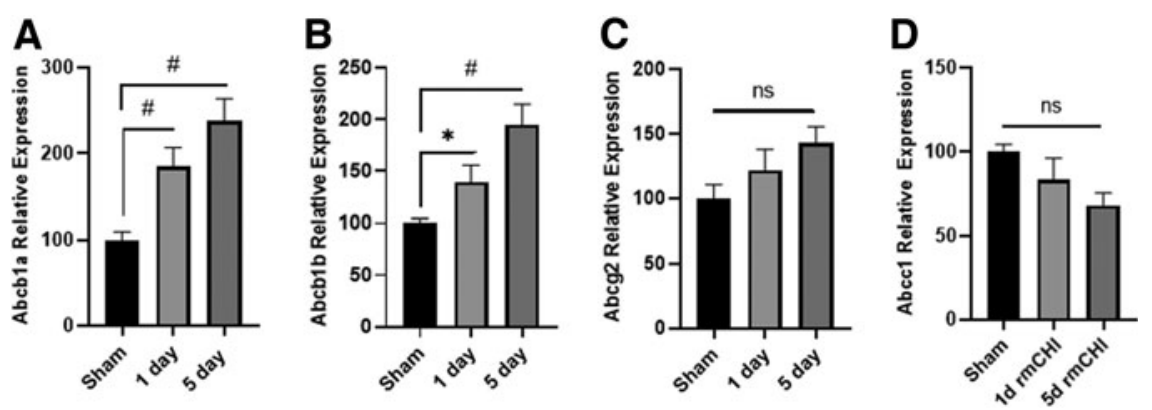

FIG. 2. RT-PCR of $A B C$ transport proteins in Sham, 1 day post-rmCHI, and 5 days post-rmCHI. Expression shown as normalized to L32. (A) Abcb1a; (B) Abcb1b; (C) Abcg2; (D) Abcc1. Overall effect is shown. *denotes $p<0.05$; \#denotes $p<0.01$. ABC, ATP-binding cassette; rmCHI, repeat mild closed head injury; $\mathrm{RT}-\mathrm{PCR}$, real-time polymerase chain reaction.

significantly increased both 1 and 5 days after rmCHI $\left(\mathrm{F}_{(2,13)}=13.79 ; p<0.01\right)$.

Effect on rmCHI on mRNA expression of BBB components

Because Pgp is only responsible for substrate efflux out of the brain, we examined if rmCHI also elicited changes in the expression of proteins that make up the $\mathrm{BBB}$, which regulates the influx of substances from circulation into the brain. The mRNA levels for the tight junction proteins claudin 5 (Cldn5; Fig. 5A; $\left.\mathrm{F}_{(2,12)}=5.65, p<0.05\right)$, and zona occludens (Zo-1, also called Tjp1; Fig. 5B; $\left.\mathrm{F}_{(2,12)}=7.05, p<0.01\right)$ were significantly increased at both 1 day and at 5 days postinjury. In contrast, mRNA expression for claudin 1 (Cldn1; Fig. 5C; $\left.\mathrm{F}_{(2,12)}=9.57, p<0.01\right)$ decreased over

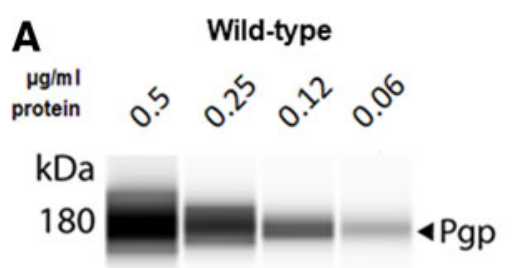

116

66

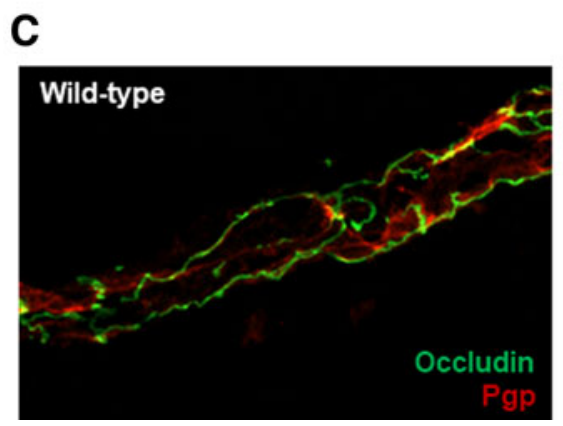

B

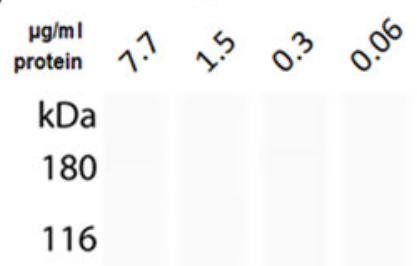

66

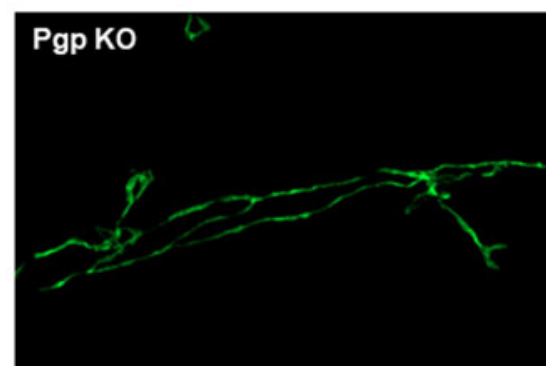

FIG. 3. Validation of AbCam anti-Pgp antibody (\#ab170904). (A) Antibody validation in wild-type animals via Wes. (B) Antibody validation in $\mathrm{KO}$ animals via Wes. (C) Antibody validation via confocal imaging in wild-type and KO animals. Overall effect is shown. *denotes $p<0.05$; \#denotes $p<0.01$. KO, knockout; Pgp, P-glycoprotein. 
A
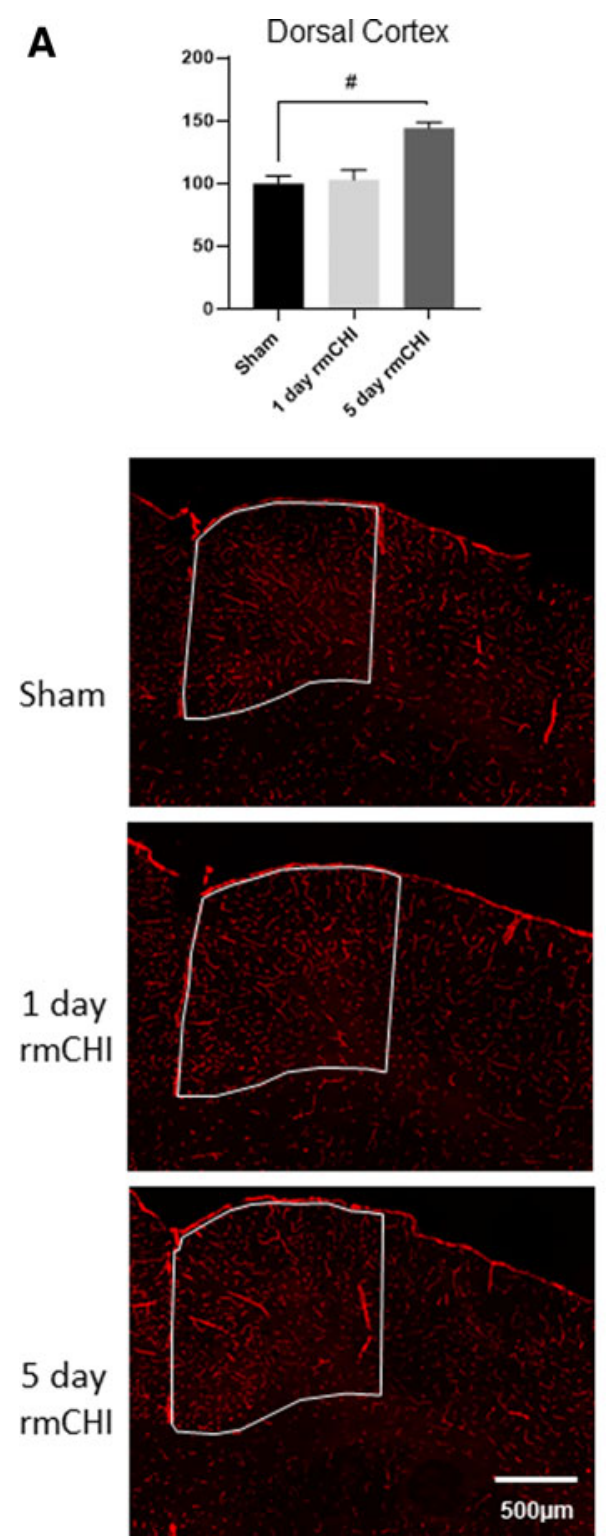

B
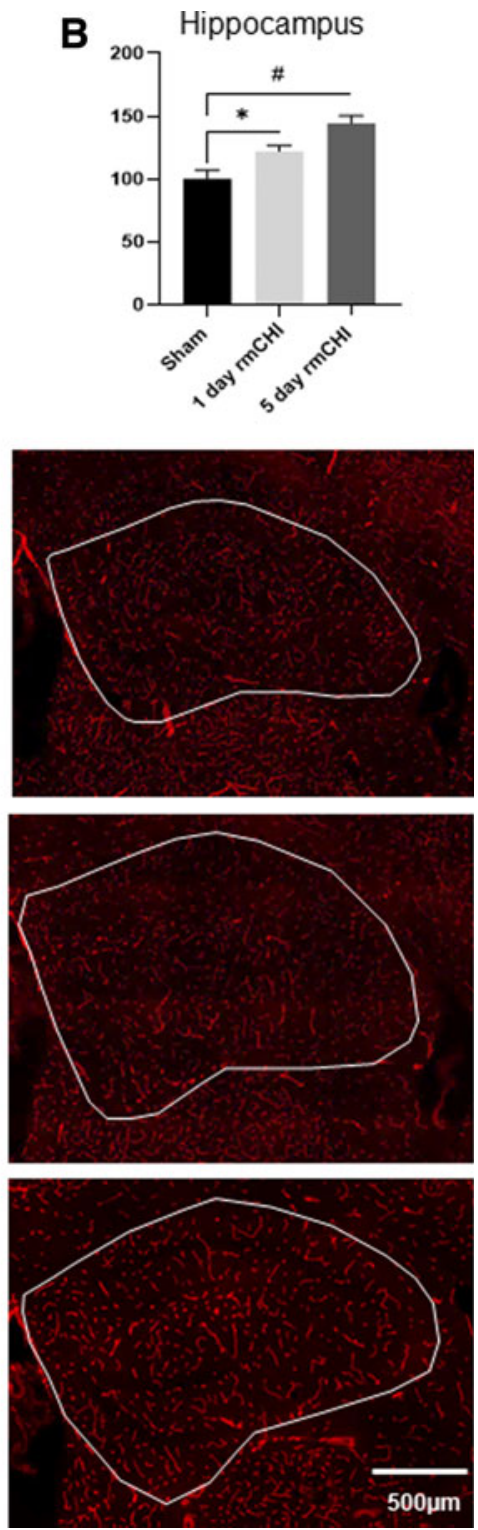

FIG. 4. Immunolabeling of $\mathrm{P}$-glycoprotein (Pgp) in sham, 1 day post-rmCHI, and 5 days post-rmCHI. (A) Dorsal cortex; (B) hippocampus. Overall effect is shown. *denotes $p<0.05$; \#denotes $p<0.01$. Pgp, P-glycoprotein; rmCHI, repeat mild closed head injury.

time, and was significantly different by 5 days postinjury. No difference in the expression of occludin was detected at either time-point (Ocln; Fig. 5D; $\mathrm{F}_{(2,12)}=$ 0.45 , n.s.).

\section{Discussion}

ATP-binding cassette $(\mathrm{ABC})$ transporters line the luminal side of the brain capillary endothelium and efflux substances, both neurotoxic and therapeutic, to prevent them from crossing the BBB and accessing the brain. An increase in transporter expression can lead to a decrease in the bioavailability of therapeutic drugs in the brain tissues. Of the ABC transporters, Pgp is the most active and has a broad range of substrate specificity, making it the transporter most associated with chemotherapeutic resistance. ${ }^{7,10,23-26}$ Using quantitative RT-PCR, we show that rmCHI increases the mRNA levels for both Pgp isoforms: Abcbla and Abcblb. 

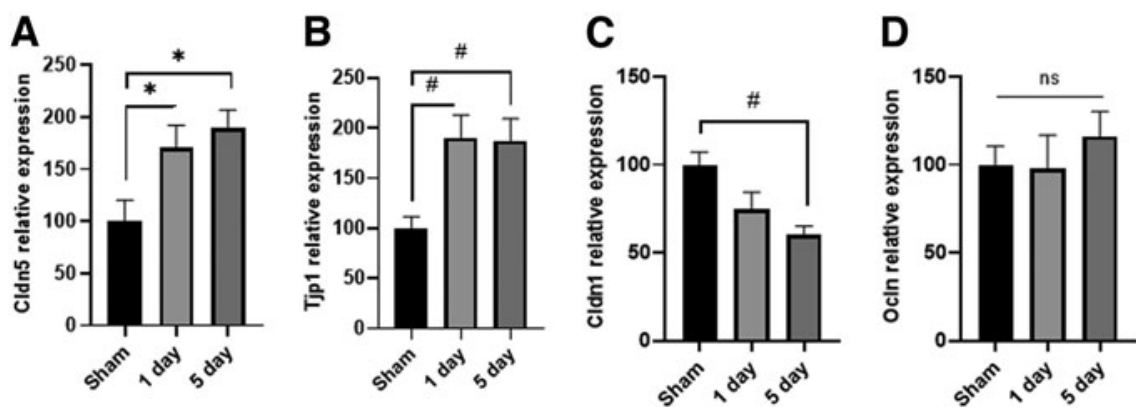

FIG. 5. RT-PCR of BBB proteins in sham, 1 day post-rmCHI, and 5 days post-rmCHI. (A) Cldn1; (B) Cldn5; (C) OcIn; (D) Tjp1. Overall effect is shown. *denotes $p<0.05$; \#denotes $p<0.01$. BBB, blood-brain barrier; Cldn1, claudin 1; Cldn5, claudin 5; rmCHI, repeat mild closed head injury; RT-PCR, real-time polymerase chain reaction; Tjp1, zona occludens.

Immunohistochemical analysis using a validated Pgp antibody indicated increased Pgp expression in the cortex proximal to the impact site as well as the hippocampus, a structure critical for learning and memory. Our results suggest that after $\mathrm{rmCHI}$, any therapeutic agents that are Pgp substrates would likely be reduced in the hippocampus and dorsal cortex, and that inhibiting Pgp may be an effective strategy to increase bioavailability of these agents, potentially increasing their efficacy to reduce the pathophysiology of repeat concussive injury.

We determined that mRNA levels of both isoforms of mouse Pgp (Abcbla and Abcblb) are significantly increased as a result of rmCHI, beginning as early as 1 day after the last injury. In addition, the mRNA levels of BCRP (or Abcg2) trended upward after rmCHI. As Pgp has the broadest substrate specificity and Abcg2 shares the most extensive overlap of substrates with Pgp, ${ }^{26-29}$ increased expression of these genes suggests that a wide range of therapeutic drugs may be actively effluxed from the luminal membrane of the endothelial cells back into the blood stream, thereby reducing their efficacy.

Pgp expression has been extensively examined in the context of cancer and other diseases due to its prominent role in limiting the action of disease-modifying therapeutic drugs. $7,9,10,30-39$ Most of these studies have used commercial Pgp antibodies. Similar to that reported previously for other Pgp antibodies, ${ }^{40-44}$ our validation results using $\mathrm{KO}$ mice revealed that some tested antibodies had poor specificity, and caution must be taken when interpreting results of studies using these antibodies.
There are some caveats associated with the current work. The present study did not explore the mechanism(s) by which rmCHI increases Pgp mRNA and protein expression. At the transcription level, factors including NFkB and p53 have been shown to bind to the promoter region of Pgp. ${ }^{45,46}$ Signaling kinases that activate these transcription factors, such as the MAPK pathway and the PI3/Akt pathway, have been shown to increase Pgp expression. ${ }^{47,48}$ Although a number of studies have shown that experimental moderate-severe TBI activates these signaling pathways, ${ }^{49-52}$ it remains to be determined if rmCHI recruits these signaling mechanisms to increase Pgp mRNA. At the translational level, microRNAs (miRs) have also been shown to regulate Pgp protein expression level. For example, miR-145 has been shown to bind to the 3'-UTR of Pgp mRNA. ${ }^{53}$ Thus, altered expression of miRNA may also contribute to the regulation of Pgp protein expression following rmCHI. Finally, the group sizes evaluated were relatively small, which may have affected the statistical power. Additional studies will be required to confirm and extend these findings.

\section{Conclusion}

Repeat concussive injury can exacerbate and prolong post-concussive syndrome (PCS) ${ }^{54-61}$ PCS can be classified into three categories: neurological (headache, disturbances in balance, vision changes, vomiting), cognitive (difficulty with concentration; problems with memory, decision making, and executive function), and behavioral (depression, insomnia, aggressive behavior). Several FDA-approved drugs (e.g., 
diazepam, tacrolimus, clozapine) are currently available to treat some of these symptoms. Unfortunately, a number of these drugs are also substrates for Pgp. As our data indicate that repeat concussive injury increases Pgp mRNA and protein expression, higher doses of these drugs may be needed to treat persons suffering from specific post-concussive symptoms (e.g., depression) resulting from repeat concussive injury. Alternatively, including a Pgp inhibitor (e.g., tariquidar, verapamil, ritanovir) with the treatment can also increase brain availability, ${ }^{62}$ and may limit unwanted side effects arising from high drug doses. Future studies could test this premise by treating rmCHI animals with a neuroprotective drug such as riluzole (a Pgp substrate) alone and in combination with a Pgp inhibitor to assess its relative effectiveness on improving outcome.

\section{Acknowledgments}

We dedicate this article to the memory of our beloved colleague and mentor, Raymond Grill.

Opinions, interpretations, conclusions, and recommendations are those of the author and are not necessarily endorsed by the U.S. Department of Defense.

\section{Funding Information}

B.E.G. and R.J.G. have been supported by the Office of the Assistant Secretary of Defense for Health Affairs, awards W81XWH-16-1-0349 and W81XWH-16-10387. Aspects of the study were made possible by funds provided to P.K.D. by the National Institutes of Health (NS087149; NS086301).

\section{Author Disclosure Statement}

No conflicting financial interests exist.

\section{Supplementary Material}

Supplementary Figure S1

\section{References}

1. Centers for Disease Control and Prevention. (2015). Report to Congress on Traumatic Brain Injury Epidemiology and Rehabilitation: Recommendations for Addressing Critical Gaps. National Center for Injury Prevention and Control; Division of Unintentional Injury Prevention. Atlanta, GA. Available from: http://www.cdc.gov/traumaticbraininjury/pubs/ congress_epi_rehab.html (Last accessed August 24, 2020).

2. Menon, D.K., Schwab, K., Wright, D.W., and Maas, A.I. (2010). Position statement: definition of traumatic brain injury. Arch. Phys. Med. Rehabil. 91, 1637-1640.

3. Numminen, H.J. (2011). The incidence of traumatic brain injury in an adult population-how to classify mild cases? Eur. J. Neurol. 18, 460-464.

4. Daneshvar, D.H., Nowinski, C.J., McKee, A., and Cantu, R.C. (2011). The epidemiology of sport-related concussion. Clin. Sports Med. 30, 1-17.
5. Roozenbeek, B., Maas, A.I.R., and Menon, D.K. (2013). Changing patterns in the epidemiology of traumatic brain injury. Nat. Rev. Neurol. 9, 231-236.

6. Vanderploeg, R.D., Curtiss, G., and Belanger, H.G. (2005). Long-term neuropsychological outcomes following mild traumatic brain injury. J. Int. Neuropsychol. Soc. 11, 228-236.

7. Dulin, J.N., Moore, M.L., and Grill, R.J. (2013). The dual cyclooxygenase/ 5-lipoxygenase inhibitor licofelone attenuates P-glycoprotein-mediated drug resistance in the injured spinal cord. J. Neurotrauma 30, 211-226.

8. Planting, A.S.T., Sonneveld, P., van der Gaast, A., Sparreboom, A., van der Burg, M.E.L., Luyten, G.P.M., de Leeuw, K., de Boer-Dennert, M., Wissel, P.S., Jewell, R.C., Paul, E.M., Purvis, N.B., and Verweij, J. (2005). A phase I and pharmacologic study of the MDR converter GF120918 in combination with doxorubicin in patients with advanced solid tumors. Cancer Chemother. Pharmacol. 55, 91-99.

9. Jablonski, M.R., Markandaiah, S.S., Jacob, D., Meng, N.J., Li, K., Gennaro, V., Lepore, A.C., Trotti, D., and Pasinelli, P. (2014). Inhibiting drug efflux transporters improves efficacy of ALS therapeutics. Ann. Clin. Transl. Neurol. 1, 996-1005.

10. Milane, A., Fernandez, C., Dupuis, L., Buyse, M., Loeffler, J.-P., Farinotti, R., Meininger, V., and Bensimon, G. (2010). P-glycoprotein expression and function are increased in an animal model of amyotrophic lateral sclerosis. Neurosci. Lett. 472, 166-170.

11. Willyerd, F.A., Empey, P.E., Philbrick, A., Ikonomovic, M.D., Puccio, A.M., Kochanek, P.M., Okonkwo, D.O., and Clark, R.S.B. (2016). Expression of ATP-binding cassette transporters B1 and C1 after severe traumatic brain injury in humans. J. Neurotrauma 33, 226-231.

12. Hylin, M.J., Orsi, S.A., Rozas, N.S., Hill, J.L., Zhao, J., Redell, J.B., Moore, A.N., and Dash, P.K. (2013). Repeated mild closed head injury impairs shortterm visuospatial memory and complex learning. J. Neurotrauma 30, 716-726.

13. Maynard, M.E., Redell, J.B., Zhao, J., Hood, K.N., Vita, S.M., Kobori, N., and Dash, P.K. (2020). Sarm 1 loss reduces axonal damage and improves cognitive outcome after repetitive mild closed head injury. Exp. Neurol. 327, 113207.

14. Franklin, K.B.J., and Paxinos, G. (1997). The Mouse Brain in Stereotaxic Coordinates. Academic Press, p. 186.

15. Goddeyne, C., Nichols, J., Wu, C., and Anderson, T. (2015). Repetitive mild traumatic brain injury induces ventriculomegaly and cortical thinning in juvenile rats. J. Neurophysiol. 113, 3268-3280.

16. Robinson, S., Berglass, J.B., Denson, J.L., Berkner, J., Anstine, C.V., Winer, J.L., Maxwell, J.R., Qiu, J., Yang, Y., Sillerud, L.O., Meehan, W.P., Mannix, R., and Jantzie, L.L. (2017). Microstructural and microglial changes after repetitive mild traumatic brain injury in mice. J. Neurosci. Res. 95, 10251035.

17. Schinkel, A.H., Mayer, U., Wagenaar, E., Mol, C.A.A.M., van Deemter, L., Smit, J.J.M., van der Valk, M.A., Voordouw, A.C., Spits, H., van Tellingen, O., Zijlmans, J.M.J.M., Fibbe, W.E., and Borst, P. (1997). Normal viability and altered pharmacokinetics in mice lacking mdr1-type (drug-transporting) P-glycoproteins. Proc. Natl. Acad. Sci. U. S. A. 94, 4028-4033.

18. Hartz, A.M.S., Zhong, Y., Shen, A.N., Abner, E.L., and Bauer, B. (2018). Preventing P-gp ubiquitination lowers $A \beta$ brain levels in an Alzheimer's disease mouse model. Front. Aging Neurosci. 10, 186.

19. Ma, D., Wang, A.C., Parikh, I., Green, S.J., Hoffman, J.D., Chlipala, G., Murphy, M.P., Sokola, B.S., Bauer, B., Hartz, A.M.S., and Lin, A.-L. (2018). Ketogenic diet enhances neurovascular function with altered gut microbiome in young healthy mice. Sci. Rep. 8, 6670.

20. Parikh, I., Guo, J., Chuang, K.-H., Zhong, Y., Rempe, R.G., Hoffman, J.D., Armstrong, R., Bauer, B., Hartz, A.M.S., and Lin, A.-L. (2016). Caloric restriction preserves memory and reduces anxiety of aging mice with early enhancement of neurovascular functions. Aging 8, 2814-2826.

21. Ponio, J.B.-D., El-Ayoubi, F., Glacial, F., Ganeshamoorthy, K., Driancourt, C., Godet, M., Perrière, N., Guillevic, O., Couraud, P.O., and Uzan, G. (2014). Instruction of circulating endothelial progenitors in vitro towards specialized blood-brain barrier and arterial phenotypes. PLoS ONE 9, e84179.

22. Zhang, Y.-K., Dai, C., Yuan, C., Wu, H.-C., Xiao, Z., Lei, Z.-N., Yang, D.-H., Le, X.C., Fu, L., and Chen, Z.-S. (2017). Establishment and characterization of arsenic trioxide resistant KB/ATO cells. Acta Pharm. Sin. B. 7, 564-570.

23. Abdullahi, W., Davis, T.P., and Ronaldson, P.T. (2017). Functional expression of $\mathrm{P}$-glycoprotein and organic anion transporting polypeptides at 
the blood-brain barrier: understanding transport mechanisms for improved CNS drug delivery? AAPS J. 19, 931-939.

24. Cordon-Cardo, C., O'Brien, J.P., Casals, D., Rittman-Grauer, L., Biedler, J.L., Melamed, M.R., and Bertino, J.R. (1989). Multidrug-resistance gene (P-glycoprotein) is expressed by endothelial cells at blood-brain barrier sites. Proc. Natl. Acad. Sci. U. S. A. 86, 695-698.

25. Miller, D.S. (2010). Regulation of P-glycoprotein and other ABC drug transporters at the blood-brain barrier. Trends Pharmacol. Sci. 31, 246-254.

26. Qosa, H., Miller, D.S., Pasinelli, P., and Trotti, D. (2015). Regulation of ABC efflux transporters at blood-brain barrier in health and neurological disorders. Brain Res. 1628, 298-316.

27. Aronica, E., Gorter, J.A., Redeker, S., van Vliet, E.A., Ramkema, M., Scheffer, G.L., Scheper, R.J., van der Valk, P., Leenstra, S., Baayen, J.C., Spliet, W.G.M. and Troost, D. (2005). Localization of breast cancer resistance protein (BCRP) in microvessel endothelium of human control and epileptic brain. Epilepsia 46, 849-857.

28. Löscher, W., and Potschka, H. (2005). Blood-brain barrier active efflux transporters: ATP-binding cassette gene family. NeuroRx 2, 86-98.

29. Maliepaard, M., van Gastelen, M.A., Tohgo, A., Hausheer, F.H., van Waardenburg, R.C., de Jong, L.A., Pluim, D., Beijnen, J.H., and Schellens, J.H. (2001). Circumvention of breast cancer resistance protein (BCRP)-mediated resistance to camptothecins in vitro using nonsubstrate drugs or the BCRP inhibitor GF120918. Clin. Cancer Res. Off. J. Am. Assoc. Cancer Res. 7, 935-941.

30. Agarwal, S., Sane, R., Gallardo, J.L., Ohlfest, J.R., and Elmquist, W.F. (2010) Distribution of gefitinib to the brain is limited by P-glycoprotein (ABCB1) and breast cancer resistance protein (ABCG2)-mediated active efflux. J. Pharmacol. Exp. Ther. 334, 147-155.

31. Agarwal, S., Hartz, A.M.S., Elmquist, W.F., and Bauer, B. (2011). Breast cancer resistance protein and P-glycoprotein in brain cancer: two gatekeepers team up. Curr. Pharm. Des. 17, 2793-2802.

32. Amin, Md.L. (2013). P-glycoprotein inhibition for optimal drug delivery. Drug Target Insights 7, 27-34.

33. Bardelmeijer, H.A., Ouwehand, M., Beijnen, J.H., Schellens, J.H.M., and van Tellingen, O. (2004). Efficacy of novel P-glycoprotein inhibitors to increase the oral uptake of paclitaxel in mice. Invest. New Drugs 22, 219-229.

34. Bihorel, S., Camenisch, G., Lemaire, M., and Scherrmann, J.-M. (2007) Influence of breast cancer resistance protein (Abcg2) and p-glycoprotein (Abcb1a) on the transport of imatinib mesylate (Gleevec ${ }^{\circledR}$ ) across the mouse blood-brain barrier: imatinib transport at the mouse blood-brain barrier. J. Neurochem. 102, 1749-1757.

35. Breedveld, P., Beijnen, J.H., and Schellens, J.H.M. (2006). Use of P-glycoprotein and BCRP inhibitors to improve oral bioavailability and CNS penetration of anticancer drugs. Trends Pharmacol. Sci. 27 17-24.

36. Chan, G.N.Y., Evans, R., Banks, D., Mesev, E., Miller, D.S., and Cannon, R.E (2017). Selective induction of P-glycoprotein at the CNS barriers during symptomatic stage of an ALS animal model. Neurosci. Lett. 639, 103-113.

37. Choo, E.F., Ly, J., Chan, J., Shahidi-Latham, S.K., Messick, K., Plise, E., Quiason, C.M., and Yang, L. (2014). Role of P-glycoprotein on the brain penetration and brain pharmacodynamic activity of the MEK inhibitor cobimetinib. Mol. Pharm. 11, 4199-4207.

38. de Klerk, O.L., Willemsen, A.T.M., Bosker, F.J., Bartels, A.L., Hendrikse, N.H., den Boer, J.A., and Dierckx, R.A. (2010). Regional increase in P-glycoprotein function in the blood-brain barrier of patients with chronic schizophrenia: a PET study with [11C]verapamil as a probe for P-glycoprotein function. Psychiatry Res. Neuroimaging 183, 151-156.

39. Di Pietro, A., Dayan, G., Conseil, G., Steinfels, E., Krell, T., Trompier, D., Baubichon-Cortay, H., and Jault, J. (1999). P-glycoprotein-mediated resistance to chemotherapy in cancer cells: using recombinant cytosolic domains to establish structure-function relationships. Braz. J. Med. Biol. Res. Rev. Bras. Pesqui. Medicas E. Biol. 32, 925-939.

40. Beaulieu, E., Demeule, M., Pouliot, J.F., Averill-Bates, D.A., Murphy, G.F., and Béliveau, R. (1995). P-glycoprotein of blood brain barrier: crossreactivity of Mab C219 with a $190 \mathrm{kDa}$ protein in bovine and rat isolated brain capillaries. Biochim. Biophys. Acta 1233, 27-32.

41. Chan, H.S., and Ling, V. (1997). Anti-P-glycoprotein antibody C219 crossreactivity with c-erbB2 protein: diagnostic and clinical implications. J. Natl. Cancer Inst. 89, 1473-1476.
42. Jetté, L., Pouliot, J.F., Murphy, G.F., and Béliveau, R. (1995). Isoform I (mdr3) is the major form of P-glycoprotein expressed in mouse brain capillaries. Evidence for cross-reactivity of antibody C219 with an unrelated protein. Biochem. J. 305 (Pt. 3), 761-766.

43. Pavelic, Z.P., Reising, J., Pavelic, L., Kelley, D.J., Stambrook, P.J., and Gluckman, J.L. (1993). Detection of P-glycoprotein with four monoclonal antibodies in normal and tumor tissues. Arch. Otolaryngol. Head Neck Surg. 119, 753-757.

44. Rao, V.V., Anthony, D.C., and Piwnica-Worms, D. (1995). Multidrug resistance P-glycoprotein monoclonal antibody JSB-1 crossreacts with pyruvate carboxylase. J. Histochem. Cytochem. Off. J. Histochem. Soc. 43, 1187-1192.

45. Goldsmith, M.E., Gudas, J.M., Schneider, E., and Cowan, K.H. (1995). Wild type p53 stimulates expression from the human multidrug resis tance promoter in a p53-negative cell line. J. Biol. Chem. 270, 18941898.

46. Zhou, G., and Kuo, M.T. (1998). Wild-type p53-mediated induction of rat mdr $1 \mathrm{~b}$ expression by the anticancer drug daunorubicin. J. Biol. Chem. 273, 15387-15394.

47. Dash, P.K., Mach, S.A., and Moore, A.N. (2002). The role of extracellular signal-regulated kinase in cognitive and motor deficits following experimental traumatic brain injury. Neuroscience 114, 755-767.

48. Yang, J.M., Vassil, A.D., and Hait, W.N. (2001). Activation of phospholipase $C$ induces the expression of the multidrug resistance (MDR1) gene through the Raf-MAPK pathway. Mol. Pharmacol. 60, 674-680.

49. Boone, D.R., Weisz, H.A., Willey, H.E., Torres, K.E.O., Falduto, M.T., Sinha, M., Spratt, H., Bolding, I.J., Johnson, K.M., Parsley, M.A., DeWitt, D.S., Prough, D.S., and Hellmich, H.L. (2019). Traumatic brain injury induces longlasting changes in immune and regenerative signaling. PLoS One 14 e0214741.

50. Jayakumar, A.R., Tong, X.Y., Ruiz-Cordero, R., Bregy, A., Bethea, J.R., Bramlett, H.M., and Norenberg, M.D. (2014). Activation of NF- $\kappa$ B mediates astrocyte swelling and brain edema in traumatic brain injury. J. Neurotrauma 31, 1249-1257.

51. Walker, P.A., Harting, M.T., Jimenez, F., Shah, S.K., Pati, S., Dash, P.K., and Cox, C.S. (2010). Direct intrathecal implantation of mesenchymal stromal cells leads to enhanced neuroprotection via an NFkappaBmediated increase in interleukin-6 production. Stem Cells Dev. 19, 867-876.

52. Zhang, X., Chen, Y., Ikonomovic, M.D., Nathaniel, P.D., Kochanek, P.M., Marion, D.W., DeKosky, S.T., Jenkins, L.W., and Clark, R.S.B. (2006). Increased phosphorylation of protein kinase $B$ and related substrates after traumatic brain injury in humans and rats. J. Cereb. Blood Flow Metab. 26, 915-926.

53. Ikemura, K., Yamamoto, M., Miyazaki, S., Mizutani, H., Iwamoto, T., and Okuda, M. (2013). MicroRNA-145 post-transcriptionally regulates the expression and function of P-glycoprotein in intestinal epithelial cells. Mol. Pharmacol. 83, 399-405.

54. Bazarian, J.J., Wong, T., Harris, M., Leahey, N., Mookerjee, S., and Dombovy, M. (1999). Epidemiology and predictors of post-concussive syndrome after minor head injury in an emergency population. Brain Inj. 13, 173-189.

55. Greco, T., Ferguson, L., Giza, C., and Prins, M.L. (2019). Mechanisms underlying vulnerabilities after repeat mild traumatic brain injuries. Exp. Neurol. 317, 206-213.

56. Lannsjö, M., af Geijerstam, J.-L., Johansson, U., Bring, J., and Borg, J. (2009). Prevalence and structure of symptoms at 3 months after mild traumatic brain injury in a national cohort. Brain Inj. 23, 213-219.

57. Lundin, A., de Boussard, C., Edman, G., and Borg, J. (2006). Symptoms and disability until 3 months after mild TBI. Brain Inj. 20, 799-806.

58. Oyegbile, T.O., Dougherty, A., Tanveer, S., Zecavati, N., and Delasobera, B.E. (2020). High sleep disturbance and longer concussion duration in repeat concussions. Behav. Sleep. Med. 18, 241-248.

59. Ryan, L.M., and Warden, D.L. (2003). Post concussion syndrome. Int. Rev. Psychiatry (Abingdon Engl.) 15, 310-316.

60. Selwyn, R.G., Cooney, S.J., Khayrullina, G., Hockenbury, N., Wilson, C.M., Jaiswal, S., Bermudez, S., Armstrong, R.C., and Byrnes, K.R. (2016). Outcome after repetitive mild traumatic brain injury is temporally related to glucose uptake profile at time of second injury. J. Neurotrauma 33, 14791491.

61. Yeates, K.O., Kaizar, E., Rusin, J., Bangert, B., Dietrich, A., Nuss, K., Wright, M., and Taylor, H.G. (2012). Reliable change in postconcussive symptoms 
and its functional consequences among children with mild traumatic brain injury. Arch. Pediatr. Adolesc. Med. 166, 615-622.

62. Center for Drug Evaluation and Research. (2020). Drug Development and Drug Interactions: Table of Substrates, Inhibitors and Inducers. U.S. Food and Drug Administration. Available from: https://www.fda.gov/drugs/ drug-interactions-labeling/drug-development-and-drug-interactionstable-substrates-inhibitors-and-inducers (Last accessed August 31, 2020).

Cite this article as: Vita SM, Redell JB, Maynard ME, Zhao J, Grill RJ, Dash PK, and Grayson BE (2020) P-glycoprotein expression is upregulated in a pre-clinical model of traumatic brain injury, Neurotrauma Reports 1:1, 207-217, DOI:10.1089/neur.2020.0034.

\section{Abbreviations Used}

$A B C=$ ATP-binding cassette

$\mathrm{ALS}=$ amyotrophic lateral sclerosis

ANOVA $=$ analysis of variance

ATP $=$ adenosine triphosphate

$\mathrm{BBB}=$ blood-brain barrier

$\mathrm{BCA}=$ bicinchoninic acid

$\mathrm{BCRP}=$ breast cancer resistance protein

$\mathrm{BSA}=$ bovine serum albumin
$\mathrm{CCl}=$ controlled cortical impact

$\mathrm{CDNA}=$ complementary DNA

Cldn $1=$ claudin 1

Cldn5 = claudin 5

$\mathrm{CNS}=$ central nervous system

$\mathrm{C}_{\mathrm{T}}=$ change in threshold cycle

ELISA = enzyme-linked immunosorbent assay

$\mathrm{FDA}=$ Food and Drug Administration

GFAP $=$ glial fibrillary acidic protein

$\mathrm{KO}=$ knockout

$\mathrm{miR}=$ microRNA

mRNA $=$ messenger RNA

$\mathrm{mTBI}=$ mild traumatic brain injury

Ocln $=$ occludin

$\mathrm{PBS}=$ phosphate-buffered saline

$\mathrm{PCR}=$ polymerase chain reaction

$\mathrm{PCS}=$ post-concussive syndrome

$\mathrm{Pgp}=\mathrm{P}$-glycoprotein

$\mathrm{rmCHI}=$ repeat mild closed head injury

$\mathrm{rmTBI}=$ repeat mild traumatic brain injury

$\mathrm{ROI}=$ region of interest

RT-PCR = real-time polymerase chain reaction

$\mathrm{SCl}=$ spinal cord injury

$\mathrm{SEM}=$ standard error of the mean

Tjp1 or Zo-1 $=$ zona occludens

WT $=$ wild type

\section{Publish in Neurotrauma Reports}

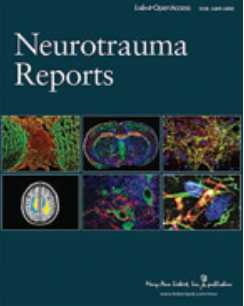

- Immediate, unrestricted online access

- Rigorous peer review

- Compliance with open access mandates

- Authors retain copyright

- Highly indexed

- Targeted email marketing

liebertpub.com/neur 